\title{
The role of IEEE computer society in the Information Age
}

\author{
Willis K. King \\ Department of Computer Science, 593 PGH, University of Houston, 4800, \\ Calhoun Blvd., Houston, TX 77204-3010, U.S.A.
}

\section{w.king@computer.org}

Abstract: The Vilnius Declaration key to success is finding a practical, affordable way to promote education. The IEEE Computer Society pioneered the use of the ICT technology to deliver continuing education to its members at an affordable cost. Through the use of the internet, our members can learn at their leisure basic elements in many popular programming languages, operating systems, data base and network systems and project management, among others. Members have free access to $100 \mathrm{Web}$-based training courses and in 2004 will have free access to 100 online reference books through our new Online Books program. They can also take a course to study elements of software engineering to help them prepare for an examination that would certify them as a qualified software engineer. The digital library provides practicing engineers and researchers key developments in the entire computing field in the last 15 years. Based on the success in the last five years, the Computer Society plans to expand this service to cover even more ground. Long-term plans include additional certification programs, such as a credential for software project management, and additional tutorials to include more advanced topics. Perhaps even in partnership with universities to facilitate the earning of academic credentials by members. The same technology and data base is accessible worldwide and can be used to help engineers and scientists in the developing countries to acquire new knowledge. With the help and cooperation of organizations such as UNESCO and other similar professional societies, we believe the IEEE Computer Society can play an important role in bridging the digital divide.

Key words: certification, Digital Divide, digital library, distance learning, Lifelong Learning 


\section{INTRODUCTION}

One of the more obvious steps to take to bridge the digital divide is to educate the population in ICT. The most cost effective way to accomplish this goal is to enlarge and enrich the educators and practitioners of ICT in the countries concerned. The IEEE Computer Society (IEEE-CS) believes that the best way to provide a large group of people with continuing education is to make use of the very technology the ICT world has developed, namely the internet. We have the experience in serving our members by delivering educational information electronically worldwide. And we believe with the co-operation of large organizations such as UNESCO, IFIPS and other national or international professional societies, we can help to advance the educational goals of the Vilnius Declaration. Our proposal is to increase and improve the quantity and quality of ICT instructors in a country in a cost effective way, who in turn can teach the general population.

The IEEE Computer Society is a global, non-governmental, not-for-profit professional society based in the U.S.A. It has over 100,000 members from over 150 countries. It is an operation unit of the IEEE, which has a global membership of over 370,000 . It publishes 23 journals in the computing area and sponsors over 150 technical conferences yearly on a worldwide basis. It has also over 200 local chapters, both for its regular and students members in six continents. Its mission, since its establishment over 50 years ago, has been to provide the computing professionals with the most comprehensive and impartial technical information. Starting about 10 years ago, the leadership of IEEE-CS realized that the traditional way of serving its members would soon no longer be adequate. People demand information instantaneously and ubiquitously. With the rapid development in the ICT area, even experienced practitioners require constant update of their knowledge in the field they practice. In other words, the IEEE-CS needs to provide its members distance education to satisfy their demand for lifelong learning. The only way that we could deliver our service to our customers effectively is to use the very technology our profession develops viz. digitally and using the internet. Starting in 1995, we offer our publication electronically with the Digital Library. Then we provide our members an email alias to facilitate electronic communication. We built an experimental virtual community on the web on distributed systems, which has since evolved to be an electronic periodical with refereed papers and open forums for over a dozen topic areas, and other community services. Since last year, we have been offering a variety of online lifelong learning services, ranging from beginning programming courses to accessing archival papers for topics in the entire information technology field. We have demonstrated that we 
can serve a large population of geographically dispersed customers at a reasonable cost. We believe the same system can be used to reach the rest of the world, where there is already a rudimentary infrastructure in internet technology.

\section{THE DISTANCE LEARNING CAMPUS}

To keep up with global competition and fast-changing technology in an Information Age economy, enterprises must quickly and effectively train employees while keeping costs within reasonable limits. e-Learning's popularity is rapidly growing as more enterprises see the benefits of an eLearning solution - e.g., lower costs, rapid learning content deployment, and scheduling flexibility.

The IEEE Computer Society pioneered the use of the ICT technology to deliver on-line continuing education to its members at an affordable cost. Through the use of the Internet, IEEE-CS members can learn at their leisure basic elements in many popular programming languages, operating systems, database and network systems, and project management, among others. At the foundation of the IEEE-CS distance learning program is the following:

- Real-world relevance - provide content that is relevant to members' jobs, balance conceptual and contextual support with realistic scenarios and technical simulations.

- Learning by doing - provide a learning experience where students actively participate in the learning process, learn by doing, and are given the best opportunity to retain and apply the new knowledge after they learn.

- Best-of-class content - provide the best content available. The content is licensed by industry leaders including Cisco Systems, Microsoft and EMC Corporation.

- Learning through collaboration - provide learning within a cooperative environment, where members can benefit from sharing their individual knowledge and experiences, or can ask an expert in the field.

- Supportive learning environment - provide students with access to hands-on labs, class tips, online chat rooms, discussion groups, $24 \times 7$ mentoring support, and relevant career resources.

- Self-directed - provide the students a tool to control the learning environment, learning at their own pace.

The IEEE-CS offers the member benefit through KnowledgeNet $\circledast$ and will soon enter the third year of this valued service. Program participation exceeds 40,000 members, since the program was introduced in February 
2002. Members may take any of the $100 \mathrm{Web}$-based training courses that cover a variety of computing programs and subjects including Java, XML, Windows, network security, database system management, Unix, and Visual $\mathrm{C}++$ to name a few. These distance-learning courses provide learners with voice, 3-D graphics, flash animation, on-screen text, and "visual sentences" that turn complex concepts into easy-to-understand images. Access to the courses is available 24 hours a day. A minimum $56 \mathrm{~K}$ Internet connection is required. The Computer Society is monitoring the usage of these courses and every six months, new courses will be introduced to replace some of the existing ones to guaranty that the most current and popular topics are included in the list.

The CS Distance Learning is gaining momentum as a program on several fronts. Based on this success, the IEEE-CS is looking for further opportunities to blend its current intellectual property, products and services with an expanded list of course offerings to satisfy the needs of its members. Tutorials that cover topics at a more advanced level are being looked at. There is even the possibility of partnering with universities to offer academic credentials.

\section{SOFTWARE PROFESSIONAL CERTIFICATION}

The three concepts in credentialing are often confused by individuals and professionals. Certification is not licensure. Licensure is not accreditation. Accreditation is not certification.

Certification is an occupational designation issued by an organization that provides confirmation of an individual's qualifications in a specified profession or occupational specialty. Certification is voluntary. That means it is neither a barrier nor a gate to entering or exiting a job. Certification implies an assurance than an individual possesses a specific knowledge or skill level pertaining to an occupation.

Accreditation is a designation that an organization or business has met a combination of standards and abilities that are put in place for public safety, welfare and confidence. Colleges are accredited. Hospitals are accredited. People are not accredited. The confusion stemming from accreditation may happen because the accreditation process may require certified or licensed professions to be part of the organization's operations.

Licensure is the most restrictive form of professional and occupational regulation. Under licensure laws, it is illegal for a person to practice a profession without first meeting state standards. Because states are different, so too can be the license and what it means, from state to state. 


\section{CSDP Certification}

Occupational certification can be broadly grouped into three areas:

1. Certifications granted by organizations or professional associations, such as the IEEE Computer Society.

2. Industry or product-related certifications, e.g. Novell Certified Engineer.

3. Certifications granted by government agencies that train for specific jobs then validate that learning and ability to perform that job can be demonstrated.

More than 200 new IT certifications have been introduced since 1997. The number of technical certifications available to IT professionals has exploded from nearly 200 to 400 in only 3 years. More than a million of these credentials have been earned. Standards will ensure quality of preparation and testing procedures, plus help identify what each certification is intended to certify. For many, a product-specific certification, such as Novell, Microsoft or Linux certifications address needs for very specific knowledge and job requirements.

The Computer Society saw the need to cut across all products and drill down to the body of knowledge that gives definition to the constellation of computer-related certification and began developing a certification program for software engineering practitioners in June 1999. Previous to that, the IEEE-CS spent several years in partnership with industrial sponsors, other professional societies and entities, collected a commonly recognized body of knowledge in software engineering (SWEBOK). At the same time, through its work in the Standards area, the Computer Society helped establish many industrial standards in software engineering. With inputs from the industry and academia, a committee of the IEEE Computer Society identified the portion of SWEBOK and standards that a practicing software engineer should master before he/she can be viewed as aqualified software professional. It specified 11 areas in software engineering and designed a test to verify the knowledge of the candidates.

The Certified Software Development Professional (CSDP) program is a professional certification for mid-level software professionals. Software engineering professionals who see that product cycles can be as short as six months and that vendor-specific certifications will require continual training and updating maybe among the first to see the value of the CSDP's standards-based certification. Professionals who have exposure or experience to different segments that are included in the entire body of knowledge that defines the software engineering profession and now wish to put the pieces together and tie everything together with a completeness and interdisciplinary advantage will find the certification invaluable. 
Generally, benefits for becoming certified may come in the form of the following.

- Additional knowledge and skills that allow you to move into a new area or perform your current job more effectively;

- Exposure to the latest software, equipment or other knowledge-based advantages you might not otherwise have;

- Increased level of expertise;

- Contact and networking with top-performing professionals in your field, around the world;

- Customer confidence based on your evidence of qualifications and suitability for the task at hand or project put out for bids;

- Added confidence.

\section{Tutorial for Software Engineering}

Complementing the launching of the certification program the IEEE Computer Society also offers a new distance-learning course. The Software Engineering Overview provides software professionals with a comprehensive review of essential software engineering principles. It also serves as a preparation course for candidates of the CSDP examination. This interactive course offers 10 modules that cover all 11 knowledge areas of the CSDP examination. Key concepts and principles of software engineering are presented with clear and concise explanations. Plus each module provides a list of references to aid in further study for each area. After completion of the course, course participants should be able to identify and understand the need for software engineering, understand software engineering principles, terms and techniques and their application to software engineering project. It also helps candidates of certification to identify areas for further review and study for the CSDP examination.

\section{COMPUTER SOCIETY DIGITAL LIBRARY}

The Computer Society library subscription package -electronic version (CSLSP-e) provides practicing engineers and researchers key developments in the entire computing field in the last 15 years. Included in the package is the entire collection of papers of the 23 periodicals published by the IEEECS from 1988 to present, and over 1200 conference proceedings (including most published by the society from 1995 forward). Since its launch in 1995, this digital library has steadily gained popularity among individuals and institutions alike. By now practically all major academic and industrial 
research libraries in the computing field are subscribers to this collection. Subscribers with access to the internet can consult the library anytime of the day and at any place in the world. We have been working diligently to enhance the accessibility of its contents by improving the search capability of the users including full text search over the 100,000 articles and papers.

\section{Other Reference Materials}

In addition to the materials published by IEEE-CS itself, beginning next year, we will offer free access to 100 online reference books to its members. Powered by Books $24 \times 7 \circledast$, the Online Bookshelf will be a unique collection of 100 business and technical books on topics including Java, .NET, project management, UML, Internet security, $\mathrm{C}++$ and more. Unlimited online access to this collection is available free to any member of the society. The IEEE-CS will also offer unlimited online access to collections of 500 and 2,400 business and technical books to members for a small subscription fee. As with the case of distance learning courses, this list of 100 freely access book will be changed periodically as users demand.

\section{CONCLUSION}

As we see from the above discussion, the IEEE Computer Society has successfully built an infrastructure to enable its members accessing information electronically at a reasonable cost. The information ranges from beginning level tutorials to the most advanced research papers in the field of computing. It allows the users to learn at their leisure and pace most current topics in programming languages, operation systems and issues in software engineering.

There are many aspects in solving the problem of the digital divide. Some require social engineering, as in the case between genders or generations. Others may need infrastructure improvement, as perhaps in the case between urban and rural areas. All require enormous amount of resources, both human and material. It is obviously beyond the capability of any single organization to solve the problem alone. However, in the case of training or upgrading a group of educators who have already some rudimentary knowledge in accessing the web and using the internet, the IEEE-CS can provide practical and affordable solution. Being a not-forprofit organization, our membership dues are already low. If a professional whose annual income is below certain preset level, we offer further substantial discount. With the aid and cooperation of organizations such as 
UNESCO, IFIPS, and other national professional societies, we believe the IEEE Computer Society can play an important role in bridging the digital divide.

\section{BIOGRAPHY}

Willis K. King received the Dipl-Ing degree from the Technische Hochschule Darmstadt, Germany (1963), and a $\mathrm{PhD}$ from the University of Pennsylvania, U.S.A. (1969), both in electrical engineering. He is a senior member of the IEEE and a member of the ACM and Sigma Xi.

King has been a professor in the Department of Computer Science at the University of Houston since 1969 and served as its chair from 1979 to 1992. He worked at the IBM Laboratorien, Germany, in 1963 and 1964.

Willis King has been an active volunteer in IEEE Computer Society for more than 30 years. He was the president of the society in 2002 and serves currently as the past president. He served as vice president for area activities from 1987 to 1988 and as vice president for educational activities in 1997 and 1998. In 1999 and 2000, he was elected respectively the second and the first vice president and chaired the conferences and tutorials board of the IEEE Computer Society. He was elected and served as president-elect in 2001. Other volunteer positions he held included the local chapter chair from 1970-1975; the general chair of the second International Symposium on Computer Architecture in 1975, the IEEE Computer Society Southwestern Regional chair from 1976 to 1982 , and the chair of the Distinguished Visitor's Program from 1980 to 1986. As the vice president in educational activities, he launched the model curricula project, which generated the Curricula 2001 report.

An active volunteer in computer science accreditation activities since the early 1980s, he served as an officer of the Computing Sciences Accreditation Board (CSAB) from 1985 to 1997, including as its president from 1993 to 1995.

King received the Outstanding Contribution Award from the IEEE Computer Society in 1988, the Distinguish Service Award from the Computing Science Accreditation Board in 1991 and 1993, and the Meritorious Achievement Award from the Educational Activities Board of the IEEE in 1994. In 2003, he was elected fellow of CSAB. 


\section{REFERENCES}

IEEE Software Engineering Standards Collection: 2003 Edition, IEEE Press 2003

Pierre Bourque and Robert Dupuis (Editors) Guide to the Software Engineering Body of Knowledge SWEBOK, CS Press Dec. 2001. 